\title{
TETRAPOD FRACTURE: SURGICAL ANATOMY REVISITED AS A GUIDE FOR 3D REDUCTION USING CARROLL GIRARD T-BAR SCREW
}

\author{
Prasetyanugraheni Kreshanti ${ }^{*}$, Livia Faranita Gianni ${ }^{1}$
}

1. Universitas Indonesia, Department of Surgery, Division of Plastic Reconstructive and Aesthetic Surgery, RSUPN Cipto Mangunkusumo, Jakarta, Indonesia

\begin{abstract}
Background: Zygomaticomaxillary complex plays a key role in the structure, function, and aesthetic appearance of the facial skeleton. Using Carroll Girard T-bar screw allows easy manipulation of the zygomaticomaxillary complex fracture. The goal of the treatment is three dimensional (3-D) restoration of the disturbed anatomy.

Methods: After exposing the fracture sites using technique such as lower eyelid, Dingman (lateral brow) or maxillary vestibular approach, the Carroll Girard T-bar screw is then attached to the lateral aspect of the malar eminence to freely move the zygoma according to the $\mathrm{x}, \mathrm{y}$, and $\mathrm{z}$ axis. Zygomaticosphenoid suture acts as the anatomical landmark for adequate reduction.

Conclusion: Open reduction and internal fixation is the principle of management in displaced ZMC fractures, aided by the use of Carroll Girard T-bar screw which allows easy manipulation and rotation for the zygomatic bone using the reference axis $\mathrm{x}, \mathrm{y}$ and $\mathrm{z}$.

Keyword: zygomaticomaxillary complex fracture, orbitozygomatic fracture, carroll girard $t$-bar screw, zygomaticosphenoid suture.

Latar Belakang : Zygomaticomaxillary complex (ZMC) memiliki peran penting dalam struktur, fungsi, dan estetika dari tulang wajah. Carroll Girard T-bar screw memberikan kemudahan untuk memanipulasi segmen fraktur zygomaticomaxillary complex. Tujuan tata laksana adalah reduksi fraktur searah 3 dimensi berdasarkan aksis x,y, dan $\mathrm{z}$.

Metodologi : Approach untuk fraktur ZMC dilakukan lower eyelid, Dingman (lateral brow) dan maxillary vestibular. Carroll Girard T-bar screw kemudian ditempatkan pada bagian lateral dari malar eminence untuk mereduksi segmen fraktur searah aksis $\mathrm{x}, \mathrm{y}$ dan $\mathrm{z}$. Sutura zygomaticosphenoid berperan sebagai landmark anatomi untuk mereduksi segmen fraktur.

Kesimpulan : TReduksi terbuka dan fiksasi internal adalah prinsip tatalaksana fraktur ZMC yang displaced, dibantu oleh penggunaan Carroll Girard T-bar screw yang memudahkan manipulasi dan rotasi zygoma searah aksis x, y dan z.

Kata Kunci : zygomaticomaxillary complex fracture, orbitozygomatic fracture, carroll girard t-bar screw, zygomaticosphenoid suture.
\end{abstract}

Received: 27 February 2017, Revised: 10 June 2017, Accepted: 26 September 2017.

Presented in PIT Perapi, Makasar, South Sulawesi, Indonesia

ISSN 2089-6492 ; E-ISSN 2089-9734

This Article can be viewed at www.jprjournal.com 


\section{INTRODUCTION}

There are 409 patients with craniomaxillofacial injuries from 2009 to 2013 (81 cases per year in average) in Cipto Mangunkusumo Hospital, among them $75 \%$ are midfacial fractures. The midface fractures mostly caused by motorcycle injuries $(75.6 \%)$ while most of the patients were male $(85.3 \%)$. These midfacial fractures cases involving 3 most common fracture sites; orbital $(21.5 \%)$, nasal $(24.1 \%)$ and zygomatic complex $(20.8 \%){ }^{1}$

The zygomaticomaxillary complex (ZMC) has this prominent profile that plays an important role in in the structural, functional and aesthetic aspect of the face. The prominent characteristic of this complex makes it vulnerable towards injury. A minimal displacement is visually noticeable.

The tetrapod itself consists of zygomaticofrontal, zygomaticomaxillary, zygomaticotemporal and zygomaticosphenoid sutures. Reduction according to the 3D alignment is tricky, so the zygomaticosphenoid bones acts as an anatomic landmark for the diagnosis and reduction of zygomaticomaxillary complex (ZMC) fracture. The axial CT scan is the most preferable imaging that shows adequate visualization of the fracture. Using the Carroll-Girard T-bar screw will help to easily rotate and further manipulation of the ZMC according to the 3D axis. For adequate visualization of the fracture site and reduction, we perform lower eyelid, Dingman (lateral brow), and maxillary vestibular approach.

\section{Anatomy}

The center part of the zygomaticomaxillary complex (ZMC) has the most prominent portion called malar eminence, located approximately 2 $\mathrm{cm}$ inferior to the lateral canthus. ${ }^{2}$ There are four bony attachments (sutures); zygomaticofrontal (superior attachment to the frontal bone), zygomaticomaxillary (medial attachment to the maxilla), zygomaticotemporal (lateral attachment to the temporal bone) and zygomaticosphenoid (deep attachment to the greater wing of the sphenoid bone).2,3 (Figure 1.) These bones provide the appropriate contour of the cheek by forming the anterior portion of the lateral orbital wall and separate the orbital contents from temporal fossa and the maxillary sinus.
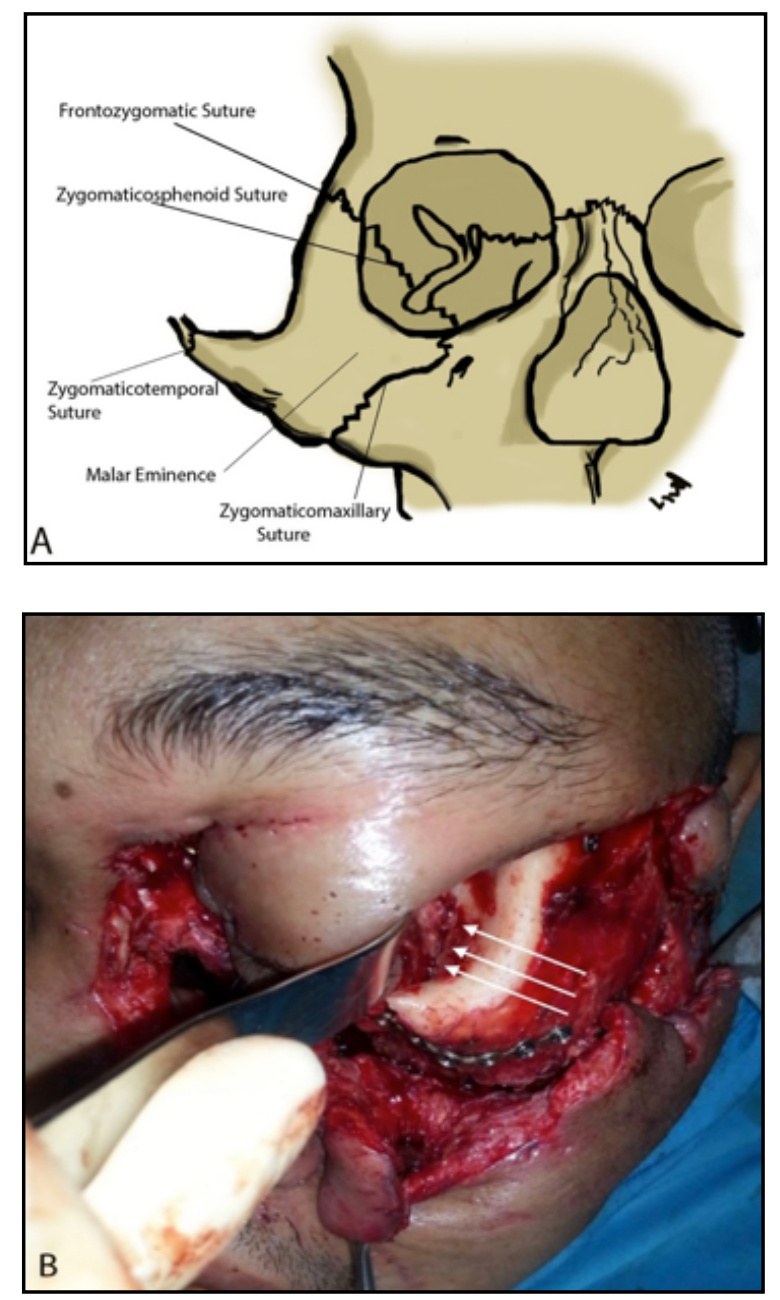

Figure 1. 1A. The Zygomaticomaxillary Complex. 1B. Zygomaticosphenoid Suture

The zygomaticosphenoid bone is the thickest portion of the lateral orbit wall and rarely comminuted. This portion of the orbit has a distinct shape and longest interaction of the zygoma with the rest of the facial bones. This gives the idea that the zygomaticosphenoid bones are the single most reliable indicator of anatomical alignment in three dimensions; $\mathrm{x}, \mathrm{y}$ and $\mathrm{z}$ axis respectively.,4 Based on Karlan's approach on the 3-D axis concept, the ZMC had three axes intersecting at the malar eminence. ${ }^{5}$ The $x$-axis (horizontal) is represented by a line through the inferior orbital rim and extending horizontally onto the surface of the zygomatic arch.

Disclosure: The authors have no financial interest to disclose. 
The y-axis (vertical) is represented by a vertical line extending from the frontozygomatic suture line inferiorly along the lateral wall of the orbit. The $z$ axis is represented by a line drawn perpendicular to the malar eminence and parallel to the lateral wall of orbit. (Figure 2).

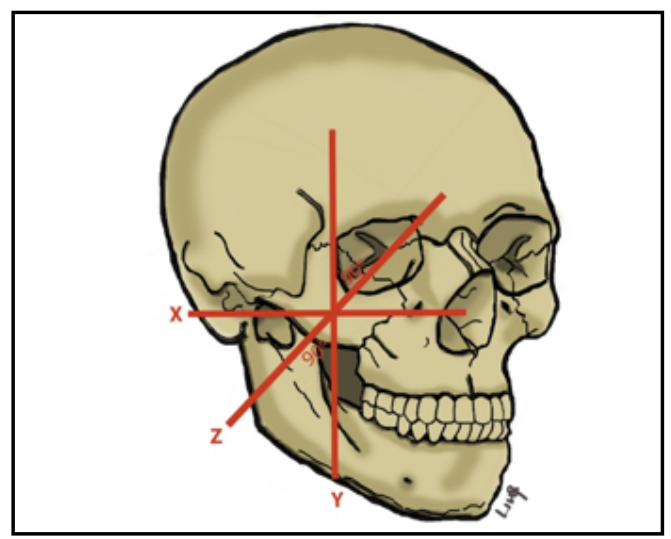

Figure 2. Three Dimensional Axis.

\section{Diagnosis}

It is important to obtain the history of the trauma to determine the mechanism and direction of the injury. It is possible that the facial swelling masks the clinical presentations and tends to minimize the degree of deformity. The swelling usually resolves sufficiently by approximately 2 weeks after the injury which makes early evaluation of the underlying deformity becomes difficult. ${ }^{3}$ (Figure 3 ).

CT scan plays an important role to evaluate the degree of the ZMC fracture displacement. The 3-D imaging itself did not show adequate visualization of fracture displacement compared to the axial CT scan. (Figure 4).
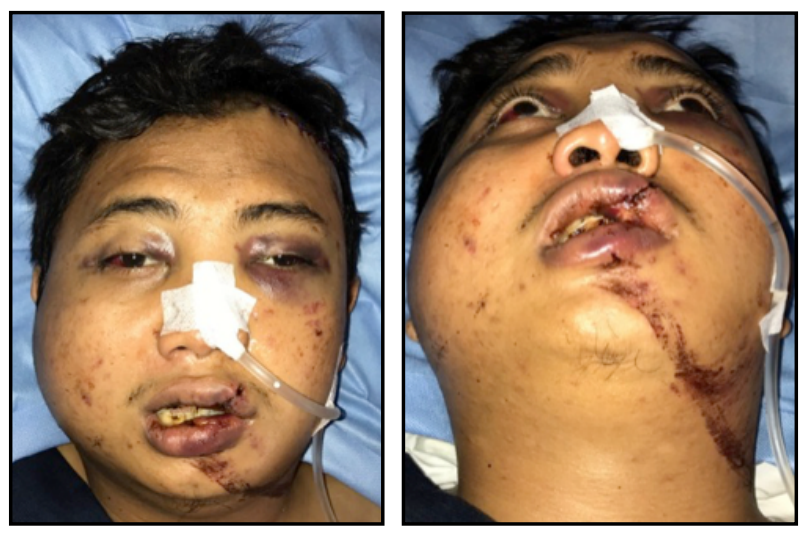

Figure 3. Severe swelling in clinical findings masked the underlying anatomic displacement of the $\mathrm{ZMC}$.

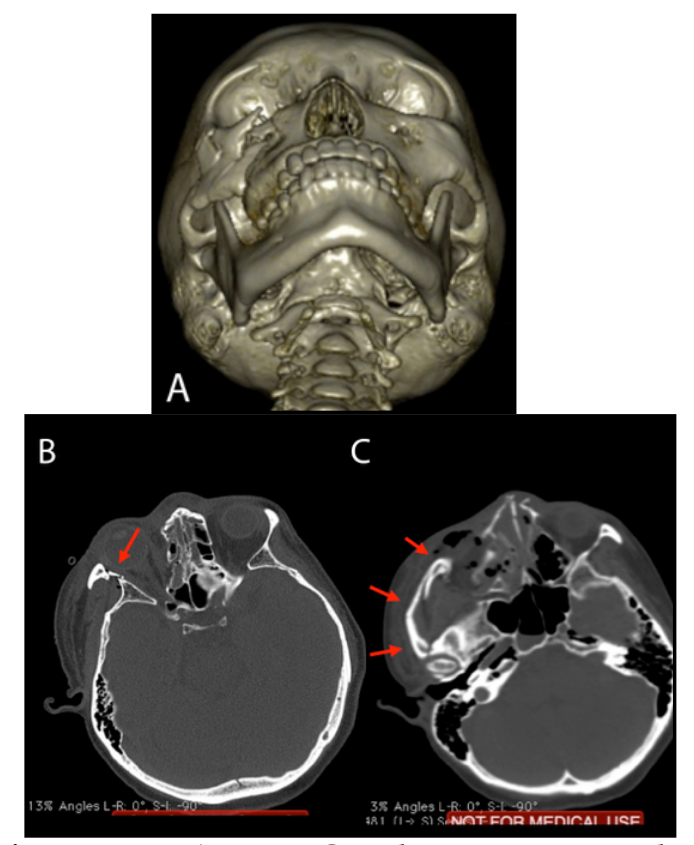

Figure 4. 4.A. 3D CT does not give clear visualization of the displacement of ZMC fracture. Axial CT scan (below) visualize clearly the displacement at the zygomaticosphenoid suture (B) and (C) zygomatic arch which will disturb the anteroposterior projection of the midface and facial width.

The goal of skeletal reconstruction must include the restoration of anteroposterior projection and facial width. Zygomatic arch held the maximal width of the face, and its alignment with the zygoma gives the definition of facial AP projection. $^{3}$

The direction of the blow and impact might lead to the better understanding of the classification. Knight and North classification are based on anatomic alteration, there are group I through $\mathrm{VI}^{2}$, 7 :

I. No significant displacement; fractures visible on radiograph, but fragments remain in line $(6 \%)$

II. Arch fractures, which involve Inward buckling of the arch with no orbital or anterior involvement (10\%)

III. Unrotated body fractures; downward and inward displacement, but no rotation $(33 \%)$

IV. Medially rotated body fractures; downward, inward, and backward displacement with medial rotation $(11 \%)$

V. Laterally rotated body fractures; downward, backward, and medial displacement with lateral rotation of the zygoma (22\%)

VI. All case in which additional fracture lines cross the main fragment (18\%) 
Knight and North indicated that groups II and V required only closed reduction without fixation, whereas groups III, IV, and VI required fixation. Further research by Pozatec et al noted that group V fractures were unstable about $60 \%$ of the time. In contrast with the Knight and North, Dingman and Natving found significant number of patient that only undergo closed reduction may suffered the relapse of the displacement. ${ }^{7}$ This may caused by the masseter muscle as the major deforming force in the fractured zygoma, resulting in disturbance of mobilization and also contributing to relapse when the fixation is inadequate. ${ }^{7}$

Manson et al, devised a CT scan based classification $^{7,9}$ :

1. Low energy fractures; incomplete fractures with minimal displacement, and the incomplete fracture itself provides the stability

2. Medium energy fractures; complete fractures at all buttresses, some displacement and comminution

3. High energy fractures; associated with other midface fractures, most severe type and often accompanied with Le Fort pan-facial fractures; these fractures can involve the glenoid fossa and produce significant posterior dislocation of the arch and malar eminence.

\section{METHODS}

Facial symmetry is achieved by restoring the 3-D position of the malar prominence, and the orbital volume is restored by the zygomaticosphenoid alignment at the lateral orbital wall. 2,3

There are many techniques for reduction of ZMC fractures, such as Gillies, Keens, or using trancutaneous screw or malar hook. It would be difficult to visualize the fracture site using Gillies and Keen techniques because they are closed reduction techniques, so the adequate reduction according the $\mathrm{x}, \mathrm{y}$, and $\mathrm{z}$ axis might be harder to achieve. Meanwhile, using transcutaneous screw or malar hook is usually done through lower eyelid, maxillary vestibular and Dingman approach (Figure 5). These approaches will easily visualize the zygomaticosphenoid suture to ensure the reduction of the ZMC fracture across the $\mathrm{x}, \mathrm{y}$, and $\mathrm{z}$ axis. The handling of the transcutaneous screw or malar hook is not ergonomic, making the maneuver to move the ZMC across the $\mathrm{x}, \mathrm{y}$, and $z$ axis relatively tricky. The T-bar handle of the Carroll Girard screw facilitates the hand grip to manipulate $\mathrm{ZMC}$ across the $\mathrm{x}, \mathrm{y}$, and $\mathrm{z}$ axis.

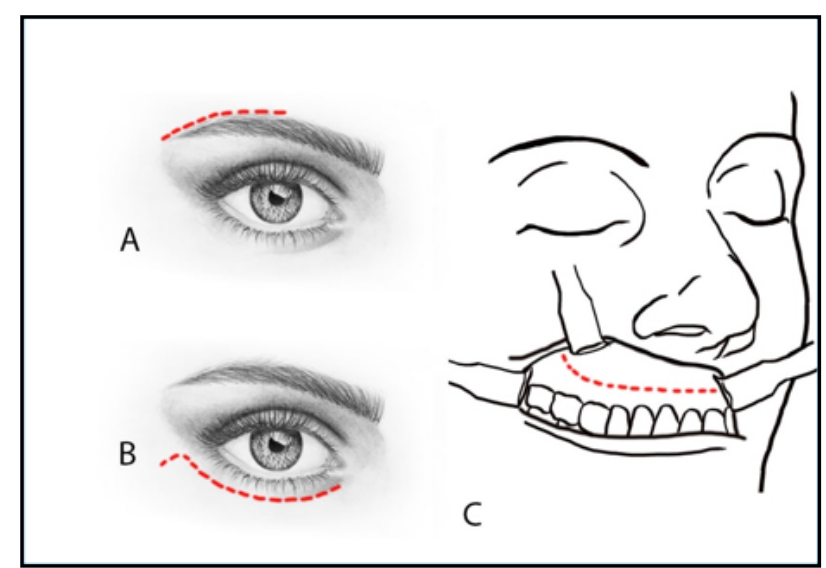

Figure 5.A. Lateral brow approach (Dingman), B. Lower eyelid Approach and C. Maxillary vestibular approach..

\section{DISCUSSION}

The Carroll Girard Screw is a useful tool for three dimensional manipulation of the complex. This screw can be placed through the lower eyelid incision into the substance of malar eminence. ${ }^{6}$ The T-Bar screw is introduced into the drilled opening and rotated in a clockwise direction until it is firmly placed within the bone, usually a depth of 10 to $20 \mathrm{~mm}$, depends on the length of the screw. ${ }^{6}$ After direct visualization is achieved, the zygomatic bone can be anatomically restored. The principal of the reduction is manipulation through the opposite direction of the displacement (fig 2). In right ZMC fracture, medially rotated fracture can be manipulated by pulling it in the opposite direction (laterally) to pivot around the y-axis. Meanwhile, laterally rotated ZMC fractures can be manipulated by rotating it around the y-axis medially. (Figure 6).

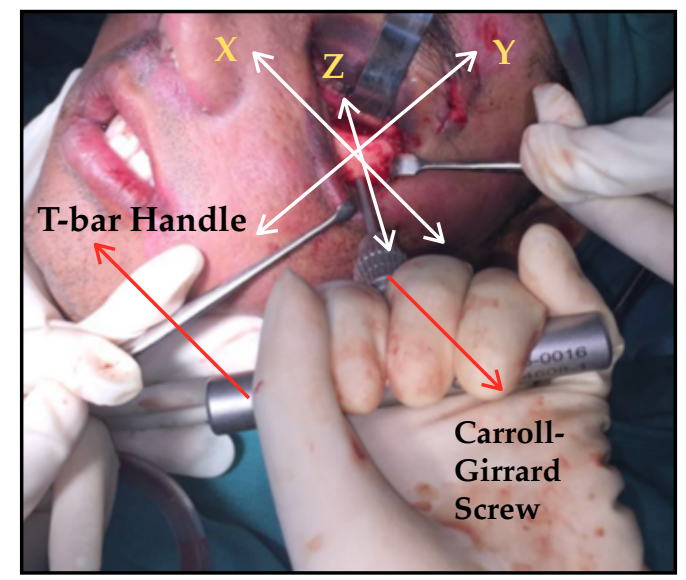

Figure 6. The Carroll Girard T-bar Screw 
Rigid fixations are standard procedure to stabilize the reduced fracture. ${ }^{9}$ The best site for rigid fixation is the zygomaticomaxillary buttress (1-point fixation), because it gives antagonistic effect to the pull of masseter muscle, in addition, this site of fixation is deep and the plates are rarely felt in this area. ${ }^{5}$ Then it is advisable to use long and strong fixation plate $(2.0 \mathrm{~mm})$. The frontozygomatic suture line are thick enough to be ideally used for rigid fixation (2-point fixation). The downside is, plate that placed in this area is quite palpable, so smaller plates are advisable. A $1.7-2.0 \mathrm{~mm}$ are recommended for inferior orbital rim (3-point fixation) in the presence of an ipsilateral nasoorbitoethmoid fracture. ${ }^{8}$ A 4-point fixation maybe needed to restore the proper projection in all three dimensions. Accurate positioning of zygomatic arch fractures will restore AP projection and width of the midface. A straight plate is recommended since zygomatic arch is not a true arch. (Figure 7).

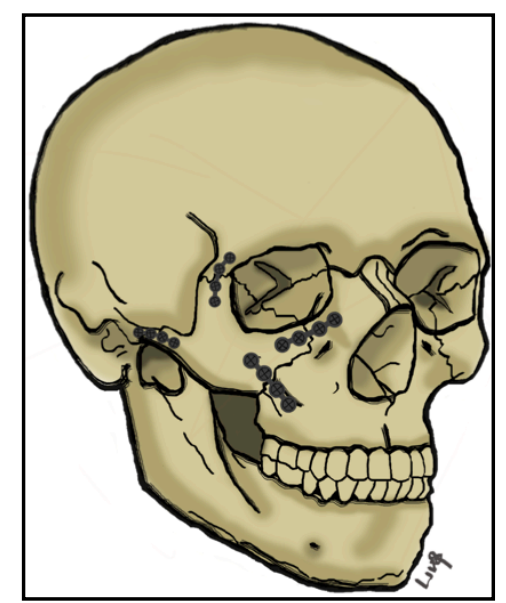

Figure 7. ZMC fracture plate fixation

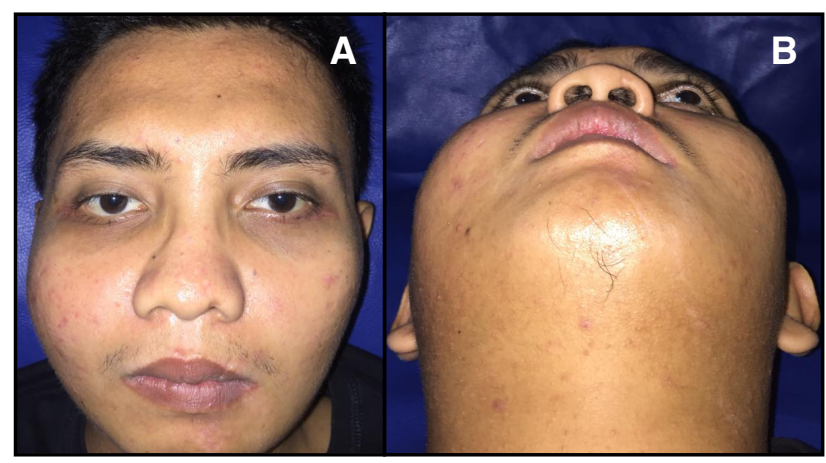

Figure 8. A. (upper left) AP view after 2 months follow up, B. (upper right) worm's eye view

\section{SUMMARY}

It should be emphasized that the understanding of the anatomy and characteristics of ZMC is important to determine the treatment of $\mathrm{ZMC}$, such as selections of approach and fixation plans. Besides obtaining a comprehensive history of trauma and physical examination, diagnosis should be supported with adequate imaging such as axial CT scan to obtain the degree of damage to the ZMC.

Open reduction and internal fixation is the principle of management of displaced ZMC fractures, aided by the use of Carroll Girard Tbar screw that allows easy manipulation and rotation for the zygoma using the reference axis $\mathrm{x}, \mathrm{y}$ and $\mathrm{z}$.

\section{Corresponding author :}

Prasetyanugraheni Kreshanti

pras_md@yahoo.com

\section{REFERENCES}

1. Tania V, Handayani S, Susanto I. A Five Year Retrospective Study of 409 Patients Presenting With Maxillofacial Fractures In Ciptomangunkusumo Hospital. 2014.

2. Baek JE, Chung CM, Hong IP. Reduction of Zygomatic Fractures Using the Carroll-Girard T-bar Screw. Archives of Plastic Surgery. 2012;39(5):556-560. doi:10.5999/aps . 2012.39.5.556.

3. Ellstrom CL, Evans GRD. Evidence-Based Medicine: Zygoma Fractures. Plast. Reconstr. Surg. 132 (Suppl. 6), 2013. p. 1649-57.

4. Kelley P, Hopper R and Gruss J. Evaluation and Treatment of Zygomatic Fractures. Plast. Reconstr. Surg. 120 (Suppl. 2): 5S, 2007. p. 5S-15S.

5. Ellis E, Shimozato K. Zygomatic Arch. Downloaded from: $\underline{\text { https:// }}$ www2.aofoundation.org/wps/portal/surgery? showPage=approach \& contentUrl=srg/92/04A p proaches/A 50 zygomatic arch.jsp\&bone=CMF\&segment=Midface \&app roach=Zygomatic\%20arch\%20(indirect)\&Lan guage $=$ en.

6. Chang EL, Hatton MP, Bernardino R, Rubin PA. Simplified Repair of Zygomatic Fractures through a Transconjuntival approach. Ophthalmology 2005; 112: 1302-1309. 
7. Meslemani D, Kellman RD. Zygomaticomaxillary complex fractures. Arch Facial Plast Surg. 2012;14(1):62-66.

8. Mcdonald WS, Thaller SR. Zygoma Fractures. In: Facial Trauma. Florida: CRC Press. 2004. p. 364-375.

9. Millard DR Jr. Cleft Craft: The Evolution of Its Surgery. I. The Unilateral Deformity. Boston: Little, Brown, and Co.; 1976.

10. Grieves MR, et al. Evidence-Based Medicine: Unilateral Cleft Lip and Nose Repair. J Plastic Reconst Surg, 2014; 134(1):1372-1380.

11. Chen PK, Noordhoff MS, Kane A. Repair of Unilateral Cleft Lip. In: Neligan PC, ed. Plastic Surgery Principles Vol 3. $3^{\text {rd }}$ Ed. Seattle: Elsevier; 2013.

12. Demke JC, Tatum SA. Analysis and Evolution of Rotation Principles in Unilateral Cleft Lip Repair. J Plast Reconst Aest Surg , 2011; 64(1): 313-318. 